\title{
The analysis of crisis management information system in the selected states
}

\author{
Katerina Vichova ${ }^{1, *}$, Martin Hromada ${ }^{1}$ \\ ${ }^{1}$ Tomas Bata University in Zlín, Faculty of Applied Informatics, Department of Security Engineering, Nad Stráněmi 4511,76005 Zlín, \\ Czech Republic
}

\begin{abstract}
This paper focuses on crisis management information systems in the selected states. The aim of this article is to analyse the selected information systems and prepare a comparison of them. The first part of the article deals with the concept of crisis management information systems in different countries. Secondly, the paper deals with the idea of crisis management information systems in different countries. Thirdly, the article deals with information systems of crisis management in the Czech Republic. These systems are further solved using a suitably chosen method. Fourthly, the paper deals with information systems in three selected countries abroad. These states were intentionally selected according to their type and according to the diversity of territories and threatening events in these states. Next part describes the suitably chosen methods of work. Heuristic usability analyses are among the most significant. This analysis is focused on detecting the strengths and weaknesses of tested systems. The following chapter aims to introduce the results of the tested crisis management information systems. The last section summarizes the entire paper and suggests solutions for these systems.
\end{abstract}

\section{Introduction}

During life, it encounters many emergencies and crises. The whole world is threatened by many emergencies. The most common disasters are natural disasters. [1] Man lives in an environment which is permanently exposed to a diversity of more or less dangerous situations, generated by numerous factors. Extreme natural phenomena such as: storms, floods, drought, landslides, earthquakes and others, in addition to technological accidents (severe pollution, for example) and conflicting situations, may influence directly the life of every person and that of society as a whole. [2] These emergencies differ according to the location of the country, its geography, the number and size of industrial enterprises, and others. The enormous difference is also cause by geographical location of the states. States located in Central Europe (e.g., the Czech Republic) are threatened different emergency than states found by the sea (e.g., the Philippines). The countries that are located by the sea must be prepared for crises such as typhoons, tsunamis, hurricane and others. Hurricane Sandy was the second costliest hurricane in United States history. [3]

In today's era of data deluge, information fusion has increasing applications in myriad of domains like disaster relief. [4] The aim of each state is to protect its population. New technologies also present new opportunities for crisis management. The crisis management information systems (CMIS) are used to address all emergencies or crises today. The term crisis communication is associated with emergency management and the need to inform and alert the public about an event. In this case, crisis communication might refer to the community leaders' efforts to inform the public. [5]

Each state characterizes the CMIS itself. The Czech Republic specifies the CMIS as a system for acquisition and providing information, presenting information, collecting, evaluating, and storing data, retrieving, disseminating, accessing, exchanging, sorting or combining, blocking and disposing of data. [6] Information support is a process (a set of information activities) supporting information management, decision making and cognitive processes. [7]

Slovakia uses information systems to plan emergency measures and manage crises. Use of CMISs must comply with the following rules:

(a) the transmission of information to superiors, subordinates and collaborating authorities of crisis management,

(b) technical and program adaptation to function in emergencies,

(c) the security of the retained information with the highest degree of secrecy contained in the processed dossier [8].

The United States of America characterize an emergency management information system as a computer database system which is designed to support responders during emergencies by giving them detailed, real-time information, allowing them to graphically

* Corresponding author: kvichova@utb.cz 
integrate it and then transmit their decisions through the chain of incident command [9].

The CMISs are used at all levels crisis management. Firstly, they are used by Joint Rescue Service. They use them to manage the crisis more efficiently and speedily. Next, CMISs are also used in public administration which needs effective decision-making and assistance in crisis situations. Finally, they can be used at the state level. There are some significant differences among countries in the ways how-the CMISs are applied, and these differences have been little discussed so far.

This paper describes and analyzes the CMISs in the selected countries. The aim of the present paper is to give information on the diversity of the CMISs.

\section{Crisis Management Information Systems in the Czech Republic}

The Czech Republic has CMISs at two levels: state and public administration. The aim of the Czech Republic was to create a unified system for crisis management in 2004. This system should create a tool for qualified decisions, planning support, and decision-making processes. The system should respect national and international standards. The intention has not been met, and the system is not developer yet at this time. The reason for the failure of the project CMIS was mainly:

a) technological demands of the entire system,

b) inappropriate legislative determination,

c) limited amount of data and the impossibility of its continuous update.

The above reasons led to the failure of the objectives of CMIS in the Czech Republic.

The Czech Republic is divided into 14 regions. Each regional office has established a department of crisis management. This department is the organizational structure of the regional office of the region. Each region ensures preparedness of management of emergencies and crisis situations.

This small group includes four regions. Firstly, it is the South Moravian region with crisis portal KRIZPORT. Secondly, it is the Zlin region, which developed its Information, Communication and Warning System. Thirdly, it is capital city Prague with CMIS of the capital city Prague. Finally, it is the Olomouc region with application Community Cards (CC). In the next part of this article, we will analyze these systems.

\section{Crisis Management Information Systems in different states}

Each state has different CMISs and we describe three selected ones.

\section{Philippines}

The National Disaster Risk Reductional and Management Council is governed in the Philippines. This council creates crisis plans, measures, and procedures in case of a disaster and warning of residents in crisis situations.
Information support for crisis management has the highest priority due to frequent natural disasters typhoons, floods, landslides. Philippines use warning system NOAH. It is a web platform which makes it possible to display actual weather, following crisis situations (floods, storms, landslides, volcanic activity), and essential elements of critical infrastructure (schools, health facilities, stations, fire stations). We can, therefore, assume that information support for crisis management has the highest priority during response to the given threats.

\section{United States of America}

The United States of America have CMIS at the state level. It is the EIS / GEM InfoBook information system. It is a system for managing crisis situations of various kinds. Thanks to this system, users can respond appropriately to any crisis. It allows receiving, sending, and recording event management data with automatic logging and automated reporting of the situation. It also allows recording of the necessary resources for managing the emergencies. The EIS / InfoBook modularity enables users to keep a quick overview of the situation and its progress, the sources of risk in the territory or the facility, the forces and resources, their operations, and tasks, description of the region, areas, buildings regarding risks, equipment, and other aspects [10]. It allows processing of specific actions plans, hiding, and evacuation.

\section{Australia}

Australia has a CMIS at the state level too. It is Australian Inter-Sevice Incident Management System (AIIMS). This system was developed in Australia in the mid-eighties. It is a robust system for managing emergencies and crisis. The system is therefore customizable and can be used effectively to manage emergencies.

The system operates efficiently for any incident natural, industrial, civilian, and many other incidents involving the emergency response from organizations. Also, the system can be used for other events that are not considered as critical - sports and cultural events, exhibitions and conferences.

This system provides firstly a management system that coordinates the activities of all involved agencies in addressing of an emergency, secondly, an entire framework for incident management that begins with the first response and grows with the severity of a crisis. The system contains a list of resources (forces and equipment) along with operational planning [11]. 


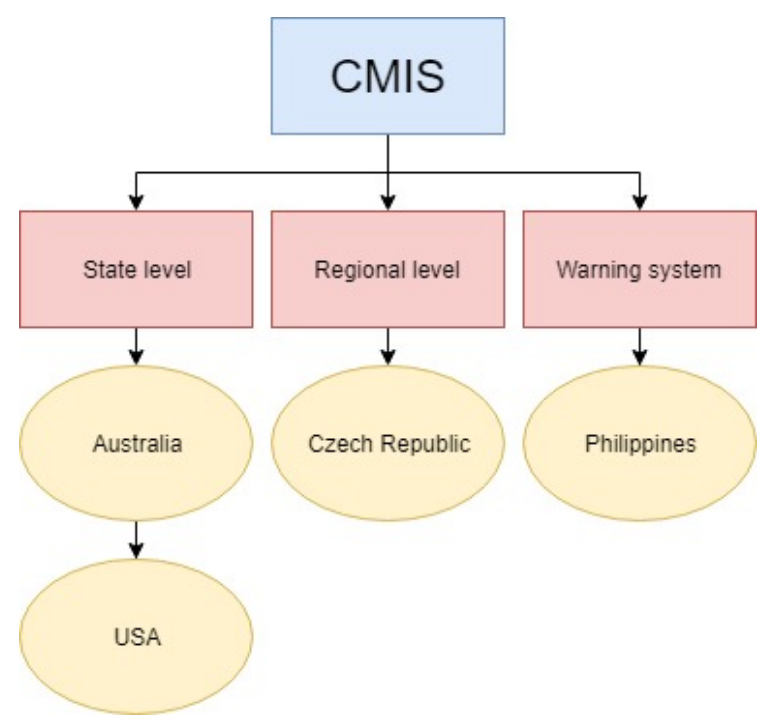

Fig. 1. Comparison of crisis management information systems.

\section{Methodology}

The CMISs have many advantages and disadvantages, and therefore the heuristic analysis of their usability was performed. This assessment is used for the qualitative evaluation of the systems. Based on the analytical studies, we determined the staff of the Fire Rescue Services and municipal Authority of the municipalities for the analysis of the information systems. We conducted an evaluation using the following equation:

$$
U I S=((\mathrm{R}+\mathrm{H}) / 2 \times \mathrm{H}) \times 100 \%
$$

Where, UIS = usability of the information system, R = sum of the results (acquired points), $\mathrm{H}=$ amount of evaluated heuristics.

A set of the evaluation questions (70 problems) was used, and these issues were divided according to several indicators. These indicators fall into six categories.

The general indicator describes the essential information from a broad perspective where this information was investigated. The next part of this indicator determines whether the system works and if we can use the system without help (user's guide). The last part solves whether the system contains only the relevant elements and information about the problem.

The second indicator is named usability. The usability finds out whether the system has the intuitiveness of the application. The next part determines the abilities firstly to control the system/application in particular conditions (in the car of Fire Rescue Service) and secondly to be adequately displayed on the mobile devices.

The third indicator is named security; it solves credibility and the possibility of the system breach. The second part of this indicator ascertains of the content of the map as actual.

The fourth indicator deals with the content of the system. This indicator solves whether the system includes any advertisements and the misleading elements.
The fifth indicator looks into the search part of the system. It observes whether the results match the searched query.

Finally, we evaluate the graphics indicator. This indicator solves the composition layout, typography, font color, and their suitability is evaluated as well as the aesthetic impression of the system [12].

The goal of the appraisal is to get feedback on the selected crisis management information system. Each item gained the following value:

$-1=$ does not meet,

$0=$ partially meets,

$1=$ satisfies,

the field is empty if the question is not relevant.

\section{Results}

This chapter aims to present the results of an evaluation of the information support for crisis management in the Czech Republic. The Czech Republic divides the information support of the crisis management to two types - state level and regional level.

An analysis of these systems has been performed. The method described in the previous chapter was used for this evaluation.

The analysis of the crisis management information system - state level

This part describes the usability of the unified CMIS. This system was only launched as a pilot version between 2008 and 2011, and it failed when it was used in a crisis during floods in Prague in 2011.

Table 1. Heuristic analysis of usability - state level [author].

\begin{tabular}{|l|l|l|l|l|}
\hline Indicators & Points & Questions & Answers & Total \\
\hline General & 2 & 12 & 10 & $60.00 \%$ \\
\hline Search & 3 & 9 & 7 & $71.43 \%$ \\
\hline Graphic & 8 & 9 & 9 & $94.44 \%$ \\
\hline Content & 6 & 9 & 8 & $87.50 \%$ \\
\hline Security & 4 & 12 & 12 & $66.67 \%$ \\
\hline Utility & -1 & 22 & 20 & $47.50 \%$ \\
\hline Total & 22 & 73 & 66 & $71.26 \%$ \\
\hline
\end{tabular}

Table 1 shows the data from the heuristic analysis of the usability of the unified crisis management information system of the Czech Republic. As can be seen, the best-evaluated category was "Graphic" which gained 95 percent. On the other hand, the category "Utility" gained only 47.5 percent. According to the evaluation, we can say that the system was partially usable. The system was under the auspices the Directorate-General of the Fire Rescue Service of the Czech Republic. This institution does not expect that the system would be reintroduced and developed in the future.

The analysis of the crisis management information systems - regional level

The information support for the crisis management in the public administration at the regional level is very diverse. Some municipalities do not use any CMISs. Only four selected regions have their CMISs, and the heuristic usability analysis was performed for them. 
Table 2. Heuristic analysis of usability - regional level [author].

\begin{tabular}{|l|l|l|l|l|l|}
\hline $\begin{array}{l}\text { Indica- } \\
\text { tors }\end{array}$ & $\begin{array}{l}\text { ICWS } \\
\text { Zlín }\end{array}$ & $\begin{array}{l}\text { Kriz- } \\
\text { port } \\
\text { Brno }\end{array}$ & $\begin{array}{l}\text { CMIS } \\
\text { Pra- } \\
\text { gue }\end{array}$ & $\begin{array}{l}\text { CC } \\
\text { Olo- } \\
\text { mouc }\end{array}$ & Total \\
\hline General & 91.66 & 95.83 & 62.50 & 86.36 & $84.09 \%$ \\
\hline Search & 100 & 83.33 & 92.85 & 0 & $69.05 \%$ \\
\hline Graphic & 100 & 100 & 83.34 & 100 & $95.84 \%$ \\
\hline Content & 87.50 & 100 & 81.25 & 77.78 & $86.63 \%$ \\
\hline Security & 87.50 & 72.73 & 85.00 & 50.00 & $73.81 \%$ \\
\hline Utility & 85.71 & 91.17 & 63.34 & 67.50 & $76.93 \%$ \\
\hline Total & 92.06 & 90.51 & 78.05 & 63.61 & $81.06 \%$ \\
\hline
\end{tabular}

Table 2 presents the results of the usability the heuristic analysis of the CMISs of municipalities. This evaluation provides the statistics data from each group of the category. As can be seen, Information, Communication and Warning system (ICWS, Zlín) was evaluated as the best one ( 92.06 percent). The search and graphic indicators of Zlin's system were evaluated as the first-rate. On the other hand, the CC did not integrate the tool "Search".

The graphic indicator of all systems used in Table 2 is evaluated as the best one. This indicator is necessary for the quick and active orientation in the system. As a result, it must be highly developed. We can conclude that these systems are usable and suitable for the further development.

\section{Discussion}

This paper dealt with the analysis of CMISs in the Czech Republic and abroad. In general, information systems are an important and essential part of planning, organizing, managing and controlling of information. That also applies to CMISs. They are used in the preparation for and handling of the crisis situations.

Each country has its own and unique CMIS. The United States of America have a unified information system. This system is used for handling diverse types of crises and emergency situations. The same kind of the system is in Australia. The Philippines use a web application to alert the inhabitants about the crisis. On the contrary, the Czech Republic has various CMISs which are divided according to two levels - country level and regional level.

A heuristic analysis of usability was selected for their evaluation. The aim of this analysis is to evaluate any information system using six indicators. The analysis was adjusted for CMISs and it contained seventy predefined questions. It was used in five CMISs. Firstly, a unified CMIS has been evaluated. Secondly, four information systems, which are used at regional levels, have been evaluated. The systems at the regional level were used and evaluated as usable. We propose to introduce a unified CMIS again.

The main weakness of information system is that the system does not determine responsibilities and competencies for the tasks in crisis management.

The first step is to unify the CMISs. Furthermore, the whole crisis management system should be customized for users. as required by them. The system should, therefore, be more user-friendly and have an intuitive interface.

We propose a new module for these systems, which will evaluate crisis preparedness of the hospital in times of crisis.

This paper was supported by the Integral Grant Agency, Tomas Bata University in Zlín IGA/FAI/2018/001 and Department of Security Engineering, Faculty of Applied Informatics.

\section{References}

1. Gathering, transmitting or losing defense information [Internet]. Available from :

http://uscode.house.gov/download/pls/18C37.txt (2012)

2. M. Cioca, L.-I. Cioca, Decision support systems used in disaster management, Decission support system (2010)

3. E. Blake et al., Tropical cyclone report hurricane sandy (2013)

4. T. Gregory, An incremental graph-partitioning algorithm for entity resolution, Information Fusion, 49 (2019)

5. C. Joane et al., Crisis emergency risk communication (2014)

6. Crisis management Act No. 240/2000, Czech Republic (2017)

7. L. Lukas, Information management in the security components (2008)

8. Managing the State in Crisis Situations in Times of War and Military Situations Act No. 387/2002, Slovakia (2017)

9. W. J. Lowe. GIS application design for an Emergency Management Information System [Internet]. Available from: http://www.giswebsite.com/lkc/refs/er/sld001.htm (1995)

10. M. Drozdek, K. Jelšovská. Information Support of Crisis Management (2013)

11. The Australian Inter-service Incident Management System. 3rd edition. [Internet]. Available from: https://www.afac.com.au (2014)

12. R. Nétek. Rich Internet Application for Support of Decision-making Processess of Integrated Rescue System (2015) 